This is the post_peer review, pre-publication version of the following article:

Holloway, J.V., Rillig, M.C., Gurnell, A.M. 2016. Underground riparian wood: Buried stem and coarse root structures of Black Poplar (Populus nigra L.). Geomorphology (2016),

http://dx.doi.org/10.1016/j.geomorph.2016.07.027.

The published version is obtainable from http://dx.doi.org/10.1016/j.geomorph.2016.07.027 0169-555X/@ 2016 Elsevier B.V. All rights reserved.

\title{
Underground riparian wood: Reconstructing the processes influencing buried stem and coarse root structures of Black Poplar (Populus nigra L.)
}

\author{
James V. Holloway ${ }^{1}$, Matthias C. Rilligig ${ }^{2,3}$, Angela M. Gurnell ${ }^{1}$ \\ 1 Queen Mary University of London, School of Geography, Mile End Road, E1 4NS \\ London, United Kingdom \\ 2 Freie Universität Berlin, Institut für Biologie, Plant Ecology, Altensteinstr. 6, Berlin D- \\ 14195, Germany \\ 3 Berlin-Brandenburg Institute of Advanced Biodiversity Research (BBIB), Berlin D- \\ 14195, Germany
}

\begin{abstract}
Following analysis of morphological (including dendrochronological and sedimentological) aspects of buried stem and coarse root structures of eight mature $P$. nigra individuals located within two sites along the middle to lower Tagliamento River, Italy (Holloway et al., 2016), this paper introduces information on the historical processes of vegetation development and river flow and links this to the form of these eight trees.

Aerial images and flow time series are assembled to reconstruct the flood history, potential recruitment periods, and vegetation cover development in the vicinity of the studied trees. This information is combined with previous morphological evidence to reconstruct the development history of each tree via three-element summary diagrams showing (i) a time series of floods, aerial imagery dates, and potential recruitment periods, with colour-coded bars indicating likely key stages in the development of the tree; (ii) colour-coded overlays on an SfM photogrammetric model of each tree; and (iii) colour-coded text boxes providing explanatory annotations.

The combined morphology-process analysis reveals complex three-dimensional underground structures, incorporating buried stems, shoots, and adventitious roots that are sometimes joined by grafting, linking the standing tree with the buried gravel surface on which it was recruited. Analysis of process data provides a firm basis for identifying and dating influential flow disturbance events and recruitment windows and shows that a relatively small number of flood events have significantly impacted the studied trees, which are mainly but not exclusively the largest floods in the record. Nevertheless, we stress that all suggested dates are best estimates in the light of the combined evidence. There is undoubted potential for building different
\end{abstract}


interpretations of belowground woody structure development in light of such evidence, but we feel that the form and timing of the developmental trajectories we have proposed are reasonable and give balanced insights into the many possible ways in which this hidden component of riparian trees may develop.

Our results are relevant to river research and management issues concerning riparian woodland, fluvial wood dynamics, and wood budgets, as they indicate (i) a large hidden volume of wood that is often ignored; (ii) complex, deep, coarse anchorage structures that have relevance for rates of fluvial wood recruitment associated with lateral bank erosion / stability or wind throw; and (iii) a wood element that may significantly affect wood transport and retention within fluvial systems.

Keywords: Populus nigra; underground wood; riparian tree recruitment; flood disturbance; riparian vegetation dynamics; root system architecture

\section{Introduction}

Although the literature is abundant on the structure and physiological function of tree roots in general, riparian tree species and the physical relevance of roots to fluvial wood dynamics have received relatively little attention. From the perspective of fluvial wood research, this is unfortunate as the roots of riparian trees must logically form an important component of wood stored within river corridors. Furthermore, root systems are likely to influence the dynamics and retention of uprooted trees within fluvial systems, although flume experiments using dowels with cross-pieces to mimic highly simplified root systems have shown only a limited effect (Bertoldi et al., 2014). Lastly, the presence of sizeable root systems on isolated, river-deposited trees has been observed to have an important hydraulic effect that contributes to pioneer landform development (e.g., Gurnell et al., 2005).

In general, tree root properties have been shown to vary between and within species and in relation to tree age and physical-chemical-biological conditions (e.g., Brassard et al., 2009; Pasquale et al., 2012; Bardgett et al., 2014). In relation to riparian trees, research has revealed important properties of the depth and root size-frequency of vertical riparian root profiles and also associations between root diameter and strength, which have led to major improvements in river bank stability modelling (Simon and Collison, 2002; Pollen et al., 2004; Pollen-Bankhead and Simon, 2010). However, with some notable exceptions - such as one study in which large roots were observed in eroding banks from a boat (Rood et al., 2011) and another in which whole tree root systems were removed from man-made canal, dam, and flood protection dikes (Vennetier et al., 2015; Zanetti et al., 2015) - root investigations of mature riparian trees have mainly been conducted using the wall-profile or 'trenching' method (Maeght et al., 2013), giving only limited insights into their architectural complexity.

Nevertheless, in a companion paper, Holloway et al. (2016) described the morphology and age of the excavated buried stem and coarse $(>\sim 1 \mathrm{~cm}$ diameter) root structures of eight $P$. nigra individuals. This research revealed a set of common features of these trees, which were located in the highly disturbed river margins of the Tagliamento River, northwest Italy, including: 
- $\quad$ rooting depths to below the bar surface where the original tree established, with many young roots also existing at depth;

- $\quad$ translocation of the main buried axis in a downstream direction;

- a main buried axis comprised mainly of stems that had become buried and then generated new shoots, including multistem vegetated patches, and adventitious roots;

- $\quad$ the presence of steps and bends in the main buried axis, associated with the generation of coarse lateral roots and reflecting the sedimentary structure of the surrounding aggraded bank sediments; and

- $\quad$ grafting of roots within and between some sampled trees.

By coupling dendrochronological dating with observations of these belowground woody structures and their immediate sedimentary environment, a tentative history of the development of the belowground structures of each tree was proposed.

In this paper, we add historical process information to the previous morphologically based reconstruction proposed by Holloway et al. (2016). We assemble information on flow disturbances and vegetation development over several decades in order to provide an integrated interpretation of the belowground woody structures associated with the investigated trees that illustrates the complexity of the development history of riparian trees and their root systems in highly disturbed river margin environments.

\section{Study area}

The Tagliamento River is located in the southern fringe of the European Alps in northwest Italy and flows $\sim 170 \mathrm{~km}$ to the Adriatic Sea. It has a flashy flow regime, with floods potentially occurring at any time of year but most commonly in spring and autumn. The climatic gradient from alpine in the headwaters to moist Mediterranean in the middle to lower reaches is reflected in a change in the dominant riparian tree species from Alnus incana and Salix eleagnos in the headwaters to Populus nigra in the middle and lower reaches (Karrenberg et al., 2003).

Previous research on broad-scale vegetation dynamics on the Tagliamento (e.g., Zanoni et al., 2008; Bertoldi et al., 2011ab; Ziliani and Surian, 2012; Henshaw et al., 2013; Surian et al., 2015) has illustrated dramatic changes in vegetation extent during and in the periods between floods; spatial differences in these dynamics in different reaches, particularly reflecting changes in moisture availability, valley confinement, and gradient; and also long-term temporal trends in vegetation extent. These strong adjustments through space and time reflect a highly disturbed environment for tree colonization and growth.

This paper focuses on eight $P$. nigra individuals located within two sites in the middle to lower reaches of the Tagliamento River: a 'northern site' between river kilometres 72 and 80 and a 'southern site' between river kilometres 113 and 116. These two sites were selected to capture differences in moisture availability that were anticipated to be higher at the northern than at the southern site as a result of downstream trends in groundwater levels. Within each site, we selected trees from different locations that appeared to represent varying exposure to river flows. In this way, we attempted to sample trees across a broad range of environmental conditions that had the potential to impact on the development of their underground stems and roots. 


\section{Methods}

The root systems of eight mature $P$. nigra individuals situated close to eroding banks of the Tagliamento River were investigated during summer 2014 and spring 2015. Each of the investigated trees was sufficiently close to the edge of a recently eroding island or floodplain margin for manual excavation and sampling of its root system to be accomplished within two to three days, but sufficiently far from the eroding edge for the tree's coarse root structure to be well preserved. The morphology of the buried main axis and coarse lateral roots, and the calibre of their immediate sedimentary environment was investigated by hand excavation, followed by structure-from-motion (SfM) photogrammetric modelling, dendrochronological dating of wood samples, and visual assessment of sediment calibre, organic content, and consolidation around each tree's main axis. The detailed results and interpretations of this work, including inferences regarding the minimum date at which floods may have disturbed these underground structures, are fully reported by Holloway et al. (2016) and are summarized in Table 1.

\subsection{River stage records}

Historical information on river stage from 1982 to present was available from the Villuzza gauge, which is located $\sim 3 \mathrm{~km}$ downstream from the northern site and $30 \mathrm{~km}$ upstream from the southern site. The gauged stage record at Villuzza has been related to geomorphological and vegetation features within the active channel at the northern site (Bertoldi et al., 2009). This previous analysis indicated that within this site a river stage of $3.0 \mathrm{~m}$ at Villuzza corresponds with inundation of the entire active tract and water levels reaching and widely inundating established island surfaces, whereas a flow stage of around $2.5 \mathrm{~m}$ at Villuzza is sufficient for inundation of lower patches of vegetation with water levels reaching the lower margins of some established islands. This does not mean that absolute stage levels are the same within the northern site as those at Villuzza, but that the Villuzza stage record has been related to inundation of characteristic vegetated features within the northern site using hourly photographs taken from two fixed cameras overlooking this section of the river (Bertoldi et al., 2009). Despite the significantly greater distance between the gauge and the southern site, there are no major intervening tributary confluences, and thus the temporal pattern of stage variations within the southern site is likely to be very similar to that at the Villuzza gauge. Because the distribution of vegetation within the active channel is closely related to the local water level (fluvial disturbance) regime and because there is no other detailed, long-term stage record available from a closer site, we used the 3.0 and $2.5 \mathrm{~m}$ stage thresholds at Villuzza to indicate flow events with the potential to significantly disturb riparian vegetation at the southern as well as the northern site.

\subsection{Recruitment modelling}

Having identified flow events exceeding 2.5 and $3.0 \mathrm{~m}$ at Villuzza as potential major vegetation disturbance events, the stage records were further examined to assess the likelihood that they could have led to vegetation recruitment. We applied a modified version of the 'recruitment box' model of Mahoney and Rood (1998) to the stage record. The main modification was to remove the condition for a particular time window (originally included to represent seed release and viability), thereby extending the model to capture potential recruitment from 
vegetative propagules, assuming that root growth rate was still the main limiting factor in these cases. The possibility of faster root growth enabled by mobilisation of larger carbohydrate stores in deposited wood (Francis et al., 2006; Francis, 2007) is acknowledged as well as undoubted differences in the response of the tap roots of seedlings of different species to water table decline (Mahoney and Rood (1998) modelled North American Populus spp.), but a conservative maximum root growth rate of $25 \mathrm{~mm} \mathrm{~d}^{-1}$ was used to provide an indicative assessment of recruitment from seedlings, deposited uprooted trees, and smaller wood fragments. Therefore, recruitment was assumed most likely when all of the following conditions were satisfied:

- declining water level following a flood at a rate no greater than $25 \mathrm{~mm} \mathrm{~d}^{-1}$ (i.e., maximum root growth rate);

- period of at least 300 days to the next flood above $2.5 \mathrm{~m}$ (i.e., a complete growing season without flood disturbance); and

- water level maintained at between 0.5 and $1.5 \mathrm{~m}$ stage, which is high enough to avoid chronic drought stress but low enough to avoid premature removal by flow disturbance).

\subsection{Aerial imagery}

Georectified aerial images were assembled from a number of sources (Table 2). Image resolution varied, but images prior to 2000 had a typical resolution of 1:20,000, whereas later images had a typical resolution of 1:10,000 or, when extracted from Google Earth (Digital Globe), were comprised of pixels that were $<0.5 \mathrm{~m}$ in size. The locations of the studied trees were superimposed onto these images. The positional error analysis conducted by Mardhiah et al. (2015) on many of the same images indicated an average ground error of $\sim 5 \mathrm{~m}$ following rectification, and thus we assumed that the true location of each tree was within a circle of $10 \mathrm{~m}$ radius centred on the tree's latitude and longitude coordinates.

Each image was inspected to assess vegetation cover changes over time in the vicinity of the studied trees, which might indicate likely dates for disturbance and recruitment. The area inspected extended to $\sim 20 \mathrm{~m}$ from the location of each tree, and vegetation cover was classified as 'bare' (i.e., vegetation absent, although small plants that were not detectable in the images may have been present), 'patches' (i.e., vegetated patches separated by exposed bare surfaces), or 'closed' (vegetation cover with a closed canopy). Where patches or closed canopy vegetation were present, the tree's location was further described according to its proximity to open, bare sediment surfaces as 'edge' (within $\sim 20 \mathrm{~m}$ of the edge of the vegetated area) or 'mid' (more than $\sim 20 \mathrm{~m}$ from the edge of the vegetated area).

\subsection{Interpretation of the development history of each tree}

Process evidence derived from river stage records and aerial images was combined with previously assembled morphological evidence (Holloway et al., 2016) from structure-from-motion (SfM) photogrammetry, dendrochronological dating, and sedimentary structures associated with the buried main axis and coarse roots of each tree.

Because details on the morphological evidence are fully presented in Holloway et al. (2016), we do not explore these in detail here. Instead, a colour-coded, three-element diagram is presented for each tree to summarise its likely development history, including the previously 
reported morphological evidence. The three-element diagram for each studied tree includes (i) a time series of floods, imagery dates, and potential recruitment periods, identifying with coloured bars the likely key stages in the development of the tree under consideration; (ii) colour-coded overlays on the SfM model (depicted perpendicular to the tree and oriented with the upstream direction on the left and downstream on the right); and (iii) colour-coded boxes providing explanatory annotations.

\section{Results}

\subsection{Flood disturbances and potential recruitment periods}

Analysis of the stage record between 1982 and 2014 at Villuzza (Fig. 1), revealed frequent flood peaks exceeding the 2.5- and 3.0-m thresholds for flow-vegetation interactions and also many potential recruitment periods. The timing of aerial images for the northern and southern sites are also indicated in Fig. 1.

Major (>3.0-m stage) floods occurred in 1982, 1984, 1990, 1993, 1996 (two peaks), 2000, 2002, and 2004 with smaller (>-2.5-m peak stage) floods in 1984, 1987, 1990, 1992, 1997, 1998, 1999, 2000, 2001, 2003, 2008, 2009, 2010, and 2012.

When the recession limbs of floods were analysed, numerous potential recruitment periods were identified over the three-decade stage record.

\subsection{Changes in vegetation cover}

Temporal changes in vegetation cover in the vicinity of the eight studied trees were extracted from aerial images (Fig. 2). These show two main trends. First, the history of vegetation development around the four trees in the northern site is more complex in time and more varied between the individual sampled trees than in the southern site. Second, despite these differences, all trees apart from N3 are located in areas that were bare of vegetation in 1986 and have generally shown an increase in cover since then. In the case of N3, although the vegetation showed a closed canopy in 1986, by the 1997 image the vegetation cover was patchy. Since then, cover has slowly increased. This image information suggests that none of the studied trees were present prior to the 1980 s and that tree N3 is located where vegetation has continued to show significant disturbance throughout the period for which image evidence is available.

\subsection{Integrated interpretation: Tree N1 (Fig. 3A)}

Following recruitment, this tree developed two main axes connected at the top of the basal gravel layer, which show two breaks of slope at the top of two distinct and thus flood-related gravel deposits. The length and shape of the lower deflected section (tilted gold line in Fig. 3A) suggests that the sapling was at least $1 \mathrm{~m}$ tall and quite inflexible at the time of the first flood. Probably only a few years later, as sediment accumulation is limited and stems remained flexible, a second disturbance event caused a further deflection and burial of the two new shoots (light green lines). Thereafter, the deep and upwardly fining deposited sediment is consistent with an increasingly sheltered site and increasingly dense vegetation, as demonstrated by the aerial imagery. Aerial imagery shows vegetation cover at this location progressing from 'bare' through 'patches-edge' to 'patches-mid' in the period 1986 to 1993. The limiting 1994 date (from tree-ring 
analysis) of the aboveground trunk dictates that both floods that caused main axis deflections must have occurred before this time, making the late 1990 and late 1993 events the most likely candidates. Consequently, the growth season of 1988 , which was also a potential recruitment period, appears to be the most likely date for the original recruitment of this tree.

\subsection{Integrated interpretation: Tree N2 (Fig. 3B)}

The aerial imagery suggests patchy vegetation colonisation of this location by 1991 , suggesting the modelled recruitment period in 1988 is the most likely for this tree. The simple form of the main buried axis and evenly distributed lateral roots indicate fairly gradual burial of the stem, which is confirmed by the lack of gravel or coarser horizons above the basal gravel layer. However, there is a downstream lean to the lower main axis and some slight deflections indicative of disturbances during early development of the belowground structures. The main stem and a lateral at the top of the first component of the main axis (junction of gold and pale green axes, Fig. 3B) date to at least 1995, placing a limit on the date of this disturbance that corresponds with the early stages of distinct vegetation patch development on the aerial images (1993 and 1996). The strongest candidate event for this disturbance is the late 1990 flood. The slight deflection indicated by the divergence between the light and dark green main axis orientations most likely dates to the 2000 flood, given the later dates of all major lateral roots above this point. Furthermore, there appears to have been very little vertical accretion in recent years, as the very highest laterals (just below the ground surface) date to before 2006 .

\subsection{Integrated interpretation: Tree N3 (Fig. 4A)}

Aerial images show significant dissection and erosion of vegetation between 1996 and 2002. Since then, the location of tree N4 has mainly remained at the edge of a vegetated area facing the river's main channel. The buried stem appears to be the apical segment of a young tree that was probably eroded from the island edge and redeposited by the late 2000 flood, judging by the age of the main axis (pre-2001, red in Fig. 4A) and the proliferation of adventitious roots from its lower side, which date to at least 2001 to 2003. The gentle upward-curve of the main axis suggests gradual deflection and burial by successive inundation events keeping pace with phototropic apical growth. However, the main axis appears to have three distinct sections (red, light green, and dark green lines; Fig. 4A), with the distal extensions of the red and light green lines indicating the remains of apical shoots, which were replaced by new dominant lateral shoots and supported by the development of adventitious roots following disturbances. The 2005 date associated with the long, upstream-pointing lateral root parallel with the bank top (blue arrow) suggests that almost all deposition occurred before 2005. To synthesise, following initial deposition of the 'parent' tree during the late 2000 flood, a lateral bud became the dominant shoot (the gold axis). This was then buried and deflected (becoming the light green axis), probably by the 2002 flood, and another lateral bud became activated, inducing a second deflection on the main axis (the initiation of the dark green axis) that extended into the main extant aboveground stem. A nylon cord tied round the original stem (red axis) appears to have led to the mortality of the lower (upstream) portion of the system around 2006/7, judged from changes in wood properties in the lower lateral roots. 


\subsection{Integrated interpretation: Tree N4 (Fig. 4B)}

Aerial imagery shows that this tree has persistently occupied a location close to the edge of a vegetated area, which developed from patchy to closed canopy cover around 1999. Information on the full extent and age of the underground components of this tree are not available because it was not fully excavated. However, the main stem dates to at least 2001 and the lowest exposed section of this tree's main axis (downward pointing red arrow in Fig. 4B) dates to before 2000 , indicating that the tree probably dates back to at least 1999. Given the dendritic structure of its early coarse root network (red arrows in Fig. 4B), the well-established vegetation cover but exposed nature of the tree's location at this time, and the root grafting observed, it is plausible that it originated as a sucker from adventitious roots expanding into the fine silt and clay deposits that had accumulated in the absence of any severe flooding since 1996. The crooked downward path of the main axis below this point and the sharp angle of branching with lateral roots suggest that this is not a buried stem but a downward-tracking root. The deflection and burial of the young stem (lower part of gold line) in gravel most likely occurred in the large flood of late 2000. The next, near-horizontal section of buried stem (upper part of gold line) appears to have been deflected in this same event because the extant aerial stem (light green line) and the stout sinker roots beneath it date to 2001 . The long duration of the 2002 flood makes it a strong candidate for being a significant contributor to the deposition of the upper layers of fine sediment, into which further adventitious roots have grown since 2003.

\subsection{Integrated interpretation: Tree S1 (Fig. 5A)}

Aerial images reveal patchy vegetation at this location from 1988 and the recruitment modelling suggests this to be a likely recruitment year. However, the dendrochronology dates (oldest main axis date is 1993) correspond with an alternative and more plausible recruitment period in 1991, possibly representing a period of secondary colonisation by expansive suckering among patches of established plants. Apparently, this young tree was flattened in the October 1993 flood (light red lines in Fig. 3A), creating the lowermost curve in the main axis (transition from dark to light red lines) and potentially leading to the trapping of fine sediments and organic material in its canopy. This resulted in the development of the patch of silt and clay that encloses the area of light red lines in Fig. 5A. At this point, a shoot apparently sprouted (gold vertical line), which later became the dominant axis. Scars in the growth rings suggest that the next major event was the summer 1996 flood, bending the tree (light green lines) almost flat once again. Much of the canopy appears to have survived this event, with a branch and the apical segment probably giving rise to the main and secondary (now diminished) buried axes, respectively. In the following period up to the late 2000 flood, it is proposed that new shoots sprouted from a node in the main axis, giving rise to the two main extant aboveground stems, and many long adventitious roots emerged from a buried node to give rise to the light blue lines. The severe distortion of older adventitious roots at this depth (e.g., sharply curved dark blue line), which date to 1999 , may be caused by exposure, disturbance, and reburial of the roots during the extreme floods of November 2000. 


\subsection{Integrated interpretation: Tree S2 (Fig. 5B)}

Aerial imagery indicates progressive vegetation establishment from bare in 1993 through patches in 1997 to 2001, to the middle of an area of closed canopy vegetation from 2002. Thus the two flood events of 1996 are strong candidates for the recruitment of this tree. The earliest wood dates to 1995 at the latest, and it is proposed that this represents a portion of an original stem (main red line in Fig. 5B) of a tree that was deposited or flattened in the summer 1996 flood. Three nodes appear to have sprouted on this deflected axis (three vertical red arrows); but only the lower two successfully established roots, while the upper and lower nodes were responsible for the stems that survived until excavation. The shoot from the middle node (a small remnant remains) may have been destroyed in the November 1996 flood, and roots may not have developed from the upper node because it was originally exposed above the sediment surface. The shoot from the lowest node developed as an independent plant with roots and shoots, and the middle and upper nodes remained connected while the rest of the original stem decomposed. Subsequently, the shoots were buried in gravel and deflected downstream and in toward the bank (light green lines), and then afterward shoots developing from the gravel surface (dark green lines) were swept in a downstream direction and buried in finer sediments (light blue lines). Both of these events must have occurred before 2000 , which is the date of the present vertical, aerial stems. In the 1997 aerial photo, the tree's location is quite exposed and, therefore, the initial deflection and gravel deposition probably occurred in the October 1998 flood, while the second deflection and deposition of fines was probably related to the October 1999 flood when the location had become more sheltered. Following the deposition of finer sediments, horizontal roots (dating to between 2001 and 2006) spread into these deposits, extending mainly in a downstream direction.

\subsection{Integrated interpretation: Tree S3 (Fig. 6A)}

The 1993 image appears to show a single deposited tree at the site, with progressive development of vegetation cover in subsequent images. The fact that roots have grafted frequently and strongly with roots from other nearby trees suggests that the stems here are all the same clone. While the slightly later dates of the excavated structures (oldest dates are 1997) suggest that they may not be original parts (or closely connected to parts) of this deposited tree, it is proposed that all the stems and their associated subaerial structures have developed from one 'parent tree', and it seems likely that this system developed from expansion of horizontal roots into fine deposits over basal gravels associated with the 1996 floods (gold lines in Fig. 6A). The wandering course of the main axis below this point (sinuous downward-pointing gold arrow) suggests it was a sinker root, while the straight but downstream-deflected axis (light green line, initial position marked by vertical gold line) above suggests this was a stem. This stem appears to have been flattened (to the position of the light green line) and buried by the October 1998 flood with a proliferation of adventitious roots then expanding in 1999 into fines deposited on the flood's falling limb (dark green lines). Other parts of the clonal root system appear to have similarly expanded horizontally at this time, grafting where their paths crossed. The last major phase of deposition at this site appears to have occurred during the late 2000 flood (light blue line), and the major vertical axis (dark blue line) is most likely a sucker that has grown up through 
the associated silty sand layer. The second highest lateral root (highest lateral dark blue arrow) dates the upper limit of this layer to 2001, whereas the distinctly sandier stratum above is probably associated with the November 2002 flood (the root marked with a purple arrow dates to 2003).

\subsection{Integrated interpretation: Tree S4 (Fig. 6B)}

The aerial imagery for this location shows that it was bare of vegetation to 1993, but there was progressive vegetation development from 1997. The recruitment model suggests that 1993 is a likely year for recruitment, particularly as the lowest part of the tree's main axis dates to at least 1994. The lowest part of the main axis (red, sinuous, downward-pointing arrow) has irregularly shaped annual rings throughout, indicating that it originated as a root tracking down between coarse gravel particles and suggesting that its junction with the other three red lines is the point of origin of this tree, with lateral roots tracking out in all directions (e.g., horizontal red lines). A flood deflected the main axis from vertical (red) to the curved gold line, and the1996 date of the main root (also gold) from the underside of this axis indicates that the shoot was flattened in the summer 1996 flood. A new shoot from a node (vertical gold line) then presumably became the dominant stem, only to be knocked down again (light green line) by another flood. This flood probably occurred in the same year, as the 1997 limiting date on the extant aerial stems dictates that the connecting axis from which they originate (vertically) must have been in position by this time. The sharp bend of the deflected stem also suggests that it was young and flexible at the time. Following the major disturbances in 1996, the deflected axis seems to have sprouted a strong distal shoot and a second shoot immediately at its base (dark green) and a further basal shoot (not illustrated), which later died. The basal shoots appear to have developed an upstream lean after destabilisation in the exceptional late 2000 flood (dark blue lines).

\section{Discussion}

5.1. Methods for assessing and reconstructing the development of the underground wood components of riparian trees

The excavation and sampling of the buried main axis and coarse roots of mature $P$. nigra individuals is time consuming, but the use of SfM photogrammetric modelling provides a detailed three-dimensional representation that has proved to be an invaluable aid to subsequent analysis and synthesis of information from several different sources. In particular, it has provided a record of stem, root, and sediment forms and structures, which are all crucial to making links with flood processes that may have damaged or disrupted trees and scoured or deposited sediments. While Holloway et al. (2016) illustrated that such a data set can be quite a reliable foundation for reconstructing riparian tree form-process interactions, dating that depends on dendrochronology alone is uncertain, particularly where annual growth rings are challenging to identify. In particular, the annual growth rings of many of the Salicaceae are quite difficult to interpret, particularly those of their buried woody components (e.g., Friedman et al., 2005).

Aerial imagery dating back to 1944 proved extremely useful in tracking vegetation dynamics in the vicinity of the studied trees. Even the relatively widely spaced ( 8 images between 1940 and 1990) and relatively coarser spatial resolution of the early photographs provided a useful characterisation of broad trends in vegetation development, but the 20 images from 1990 
to 2012 provided a near-annual time series, with many recent images providing a very high resolution, colour representation of the vegetation cover. Not only does aerial imagery confirm whether or not vegetation cover is present on a particular date, it also reveals, through the exposure of bare ground (between vegetation patches) and the proximity to continuous bare ground / water, the likely exposure of a tree to disturbance by a flood event, if one were to occur at that time.

Coupling of analysis of the high temporal resolution stage data from a single gauging site with the analysis of the excellent sequence of aerial images provided a firm basis for dating critical flow disturbance events and ensuing recruitment windows. The simple modelling of likely recruitment events was particularly valuable, as it helped to discriminate between floods that may or may not lead to recruitment.

The degree to which the combined information on vegetation colonisation and flow stage processes allowed refinement of dates relating to the historical development of each tree is summarised in Table 3. The presented dates show how it has been possible to narrow some of the broad 'window' estimates (e.g., 'early 1990s') proposed from the morphological information to identify a likely, specific year. They also show how the 'before' estimates based on analysing indistinct growth rings have been adjusted to specific dates of the most likely causal events, where the latter range from 0 to 6 years earlier than the former. Estimated recruitment dates show the largest differences, possibly reflecting very slow early growth, or damage and decay of the earliest components of the belowground system, as well as undercounting of the annual growth rings.

\subsection{Underground living wood dynamics}

Holloway et al. (2016) provided a full description, discussion, and synthesis of some common properties of the belowground woody structures associated with the studied $P$. nigra individuals. These were briefly summarised in the introduction to this paper and in Table 1. However, the analyses presented in this paper have helped to link these properties to processes of vegetation recruitment and growth and to flood disturbance, and thus to confirm or refine the dates of major events that had previously been inferred from dendrochronological dating.

The research has revealed complex three-dimensional, vertically connected, grid-like underground wood structures comprised of buried stems, shoots, and adventitious roots that are sometimes further linked by grafting between the subterranean elements of one or more trees. In all fully excavated cases, these complex systems permeated the flood deposits of the aggraded river bank to link the tree to the underlying basal gravels.

The complexity of the root systems and the development of their grid-like structures clearly relates to flood disturbances that deposit relatively coarser sediment layers and damage or bury stems to induce new shoot and adventitious root development within overlying fines. Thus, although all trees showed signs of the impact of dateable flood events, those trees that had developed through relatively finer and more homogenous sediments, indicative of less violent flow disturbances (e.g., trees N2 and N3) showed less complex buried structures than other trees. Furthermore, it is clear that substantial belowground coarse woody systems can develop in relatively short periods of time, as in the case of trees N3 and N4, which were both initiated by the 2000 flood. All of these aspects of the belowground woody structures of the studied trees 
illustrate that they provide complex anchorage structures that help to prevent the trees being recruited to the fluvial wood cycle, and they also provide highly irregular morphological components of recruited, uprooted trees that are likely to heavily influence their transport distance and the types of sites at which they may be retained. Moreover, the extensive and active living biomass presents a cache of buried dormant meristem primordia with the potential to regenerate roots or shoots rapidly following disturbance, thereby increasing the in and ex situ resilience of these riparian trees.

By combining morphological and process evidence, it is also clear that a relatively small number of the flood events have significantly impacted the studied trees, specifically: four recruitment events $(1988,1991,1996,2000)$ of the nine candidate events prior to 2002; and seven flood disturbance events $(1990,1993,1996,1998,1999,2000,2002)$ of the 15 candidate events between 1988 (the earliest recruitment date) and 2005 (the latest morphological estimate of disturbance). These events were mainly the largest floods in the record and so were virtually all $>3.0 \mathrm{~m}$ at their peak stage. Based on the 32-year length of the record analysed from Villuzza, our results indicate an average period of 8 years between major recruitment events and an average of 4 to 5 years between floods that are able to inflict notable modifications to the underground stem and root systems of the studied trees.

In a broader context, it is interesting to set our observations of these eight trees, which have all survived to maturity, into the context of larger-scale vegetation dynamics and turnover. For example, based on analysis of reach-scale vegetation dynamics from historical sequences of air photographs, Surian et al. (2015) concluded that in their study area (close to our northern site) 'vegetation turnover is remarkably rapid ... with $50 \%$ of in-channel vegetation persisting for less than $5-6$ years and only $10 \%$ of vegetation persisting for more than $18-19$ years....significant vegetation erosion is determined by relatively frequent floods, i.e., floods with a recurrence interval of ca. 1-2.5 years' (Surian et al., 2015, p. 542). Our results indicate that at times when large areas of vegetation are being uprooted or buried, the same disturbances are also impacting on the underground form of other trees that survive these events.

\section{Conclusions}

\subsection{Quality of inferences}

While we have endeavoured to present specific and reproducible results in the reported research, and we have made our best attempts at accurate explanations of the establishment and belowground development of eight $P$. nigra individuals, this type of research presents challenges in both methodology and interpretation. Given the difficulties of conducting dendrochronological dating of the target species, particularly its belowground woody components, all suggested dates (from morphology and process information sources) are best estimates in the light of the combined evidence. There is undoubted potential to develop several different interpretations of belowground woody structure development in the light of such observations, but we feel that the form and timing of the developmental trajectories proposed are among the most parsimonious uses of the limited evidence available and give reasonable and balanced insights into the many possible ways in which this hidden component of riparian trees may develop. 


\subsection{Scientific and management relevance}

We have provided insights into the structural complexity and typical size of the coarse belowground wood structures associated with standing riparian trees of the species $P$. nigra. While the quality of models generated here is not yet sufficient for accurate estimates of root system volume and biomass, refinement of the SfM protocol will allow quantitative assessments in the future. Information on the size, organisation, and development of these structures is highly relevant to any research or river management issues relating to riparian woodland, fluvial wood dynamics, and wood budgets, as it indicates (i) a large hidden volume of wood that is often ignored and that is undoubtedly important for creating erosion-resistant patches of floodplain and island sediments; (ii) the complex, deep, living and active coarse anchorage structures possessed by a widely occurring riparian tree species, which have relevance for rates of fluvial wood recruitment associated with lateral bank erosion / stability or wind throw, as well as for riparian plant community ecology and the structure and function of soil systems; and (iii) a wood element that may significantly affect wood transport and retention within fluvial systems. However, it is important to stress that the reported results relate to eight trees of one species at two locations on one river. They provide an important starting point for understanding the importance of the lifehistory of key riparian tree species for the physical dynamics of wood and river systems.

\section{Acknowledgments}

James Holloway's research is funded by the SMART Joint Doctoral Programme (Science for Management of Rivers and their Tidal Systems), which is financed by the Erasmus Mundus Programme of the European Union. Thanks is due to the reviewers and editors whose input has greatly helped improve this manuscript.

\section{References}

Bardgett, R.D., Mommer, L., De Vries, F.T., 2014. Going underground: root traits as drivers of ecosystem processes. Trends in Ecology \& Evolution 29, 692-699.

Bertoldi, W., Gurnell, A.M., Surian, N., Tockner, K., Zanoni, L., Ziliani, L., Zolezzi, G., 2009. Understanding reference processes: linkages between river flows, sediment dynamics and vegetated landforms along the Tagliamento River, Italy. River Research and Applications 25, 501-516.

Bertoldi, W., Drake, N.A., Gurnell, A.M., 2011a. Interactions between river flows and colonizing vegetation on a braided river: exploring spatial and temporal dynamics in riparian vegetation cover using satellite data. Earth Surface Processes and Landforms 36, 1474-1486.

Bertoldi, W., Gurnell, A.M., Drake, N.A., 2011b. The topographic signature of vegetation development along a braided river: results of a combined analysis of airborne lidar, colour air photographs and ground measurements. Water Resources Research 47, W06525, 13 pp.

Bertoldi, W., Welber, M., Mao, L., Zanella, S., Comiti, F., 2014. A flume experiment on wood storage and remobilization in braided river systems. Earth Surface Processes and Landforms 39, 804-813. 
Brassard, B.W., Chen, H.Y.H., Bergeron, Y., 2009. Influence of Environmental Variability on Root Dynamics in Northern Forests. Critical Reviews in Plant Sciences 28, 179-197.

Francis, R.A., 2007. Size and position matter: riparian plant establishment from fluvially deposited trees. Earth Surface Processes and Landforms 32, 1239-1243.

Francis, R.A., Gurnell, A.M., Petts, G.E., Edwards, P.J. 2006. Riparian tree establishment on gravel bars: interactions between plant growth strategy and the physical environment. In: Sambrook Smith, G.H., Best, J.L., Bristow, C.S., Petts, G.E. (Eds.) Braided Rivers: Process, Deposits, Ecology and Management. Blackwell, Oxford, UK, pp. 361-380.

Friedman, J.M., Vincent, K.R., Shafroth, P.B. 2005. Dating floodplain sediments using tree-ring response to burial. Earth Surface Processes and Landforms 30, 1077-1091.

Gurnell A.M., Tockner, K., Edwards, P.J., Petts, G.E., 2005. Effects of deposited wood on biocomplexity of river corridors. Frontiers in Ecology and Environment 3, 377-382.

Henshaw, A.J., Gurnell, A.M., Bertoldi, W., Drake, N.A., 2013. An assessment of the degree to which Landsat TM data can support the assessment of fluvial dynamics, as revealed by changes in vegetation extent and channel position, along a large river. Geomorphology 202, 74-85

Holloway, J.V., Rillig, M.C., Gurnell, A.M., 2016. Underground Riparian Wood: Buried Stem and Coarse Root Structures of Black Poplar (Populus nigra L.). Geomorphology, http://dx.doi.org/10.1016/j.geomorph.2016.08.002.

Karrenberg, S., Kollmann, J., Edwards, P.J., Gurnell, A.M., Petts, G.E., 2003. Patterns in woody vegetation along the active zone of a near-natural Alpine river. Basic and Applied Ecology $4,157-166$.

Maeght, J.L., Rewald, B., Pierret, A., 2013. How to study deep roots-and why it matters. Frontiers in Plant Science 4, article 299, 14 pp.

Mahoney, J.M., ROOD, S.B., 1998. Streamflow requirements for cottonwood seedling recruitment - An integrative model. Wetlands 18, 634-645.

Mardhiah, U., Rillig, M.C.,Gurnell, A., 2015. Reconstructing the development of sampled sites on fluvial island surfaces of the Tagliamento River, Italy, from historical sources. Earth Surface Processes and Landforms 40, 629-641.

Pasquale, N., Perona, P., Francis, R., Burlando, P., 2012. Effects of streamflow variability on the vertical root density distribution of willow cutting experiments. Ecological Engineering 40, 167-172.

Pollen, N., Simon, A., Collison, A., 2004. Advances in assessing the mechanical and hydrologic effects of riparian vegetation on streambank stability. In: Bennett, S.J., Simon, A. (Eds.) Riparian Vegetation and Fluvial Geomorphology, AGU, Washington, D.C., USA, pp. 267282 ,

Pollen-Bankhead, N., Simon, A., 2010. Hydrologic and hydraulic effects of riparian root networks on streambank stability: Is mechanical root-reinforcement the whole story? Geomorphology 116, 353-362.

Rood, S.B., Bigelow, S.G., Hall, A.A., 2011. Root architecture of riparian trees: river cut-banks provide natural hydraulic excavation, revealing that cottonwoods are facultative phreatophytes. Trees - Structure and Function 25, 907-917. 
Simon, A., Collison, A.J.C., 2002. Quantifying the mechanical and hydrologic effects of riparian vegetation on streambank stability. Earth Surface Processes and Landforms 27, 527-546.

Surian, N., Barban, M., Ziliani, L., Monegato, G., Bertoldi, W.,Comiti, F., 2015. Vegetation turnover in a braided river: frequency and effectiveness of floods of different magnitude. Earth Surface Processes and Landforms, 40, 542-558.

Vennetier, M., Zanetti, C., Meriaux, P., Mary, B., 2015. Tree root architecture: new insights from a comprehensive study on dikes. Plant and Soil 387, 81-101.

Zanetti, C., Vennetier, M., Mériaux, P., Provansal, M., 2015. Plasticity of tree root system structure in contrasting soil materials and environmental conditions. Plant and Soil 387, 21-35.

Zanoni, L., Gurnell, A.M., Drake, N.,Surian, N., 2008. Island dynamics in a braided river from an analysis of historical maps and air photographs. River Research and Applications 24, 1141 1159.

Ziliani, L.,Surian, N., 2012. Evolutionary trajectory of channel morphology and controlling factors in a large gravel-bed river. Geomorphology 173-174, 104-117. 


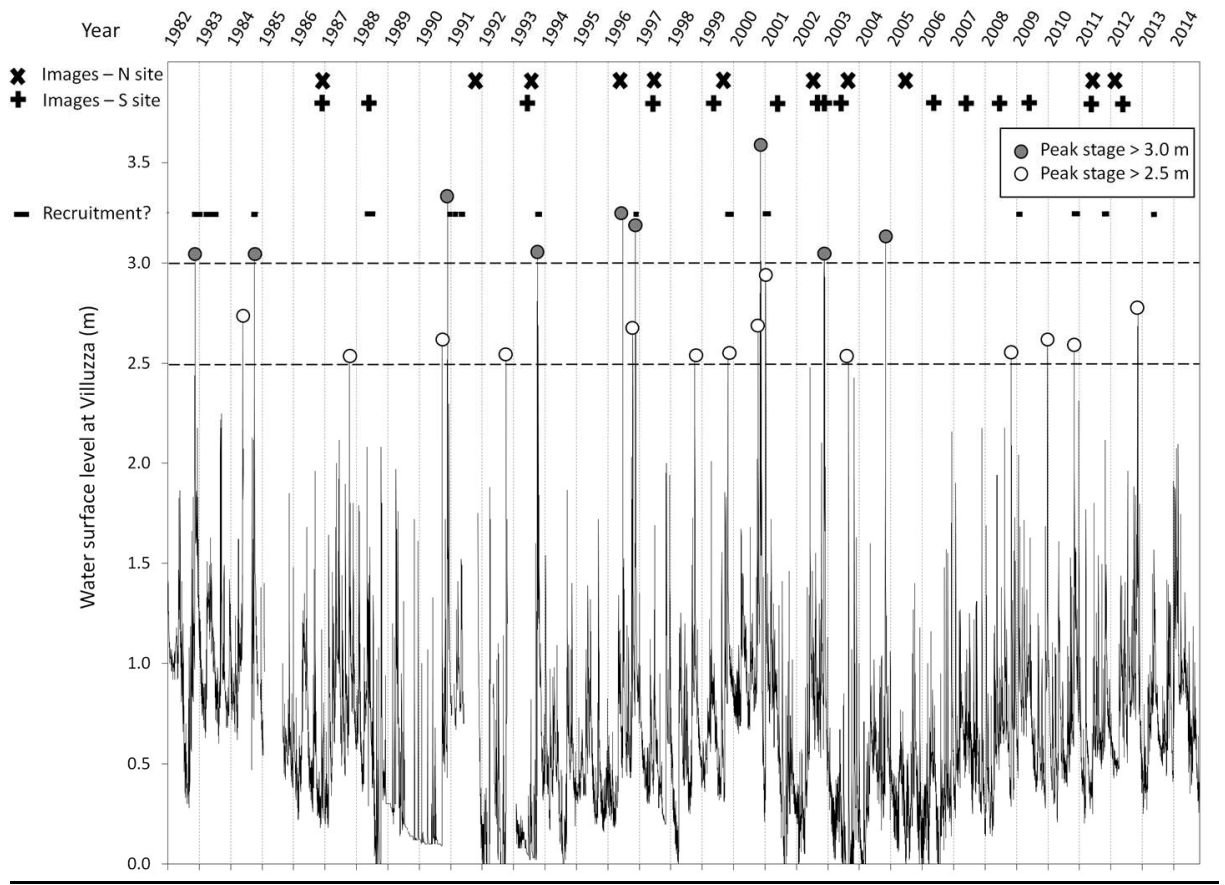

Fig. 1. Stage record at the Villuzza gauge, 1982-2014, in relation to images analysed at the northern and southern study sites, modelled potential recruitment periods, peak river stages exceeding 3.0 and $2.5 \mathrm{~m}$ at Villuzza.
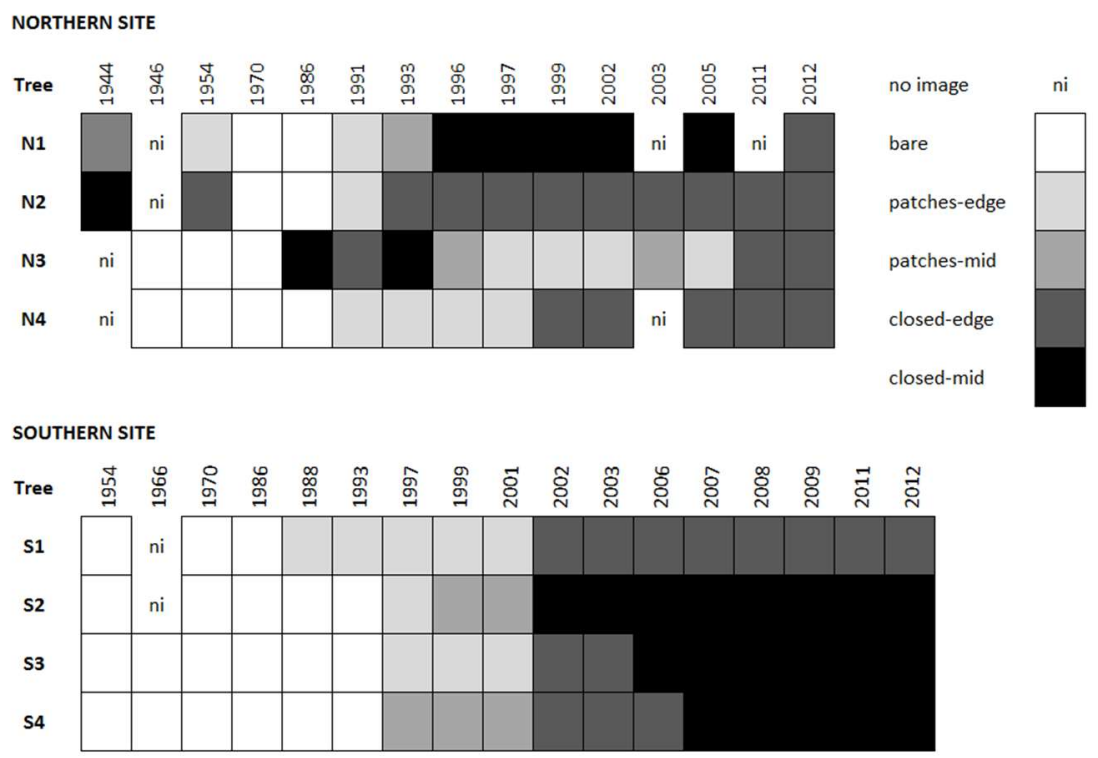

Fig. 2. Vegetation context of locations of studied trees, extracted from aerial imagery obtained during different years. Vegetation within a $20-\mathrm{m}$ radius of each tree is recorded as 'bare' (i.e., vegetation absent, although small plants that were not detectable in the images may have been present), 'patches' (i.e., vegetated patches separated by exposed bare surfaces), or 'closed' (vegetation cover with a closed canopy). Where patches or closed canopy vegetation were present, the tree's location was further described according to its proximity to open, bare sediment surfaces as 'edge' (within $\sim 20 \mathrm{~m}$ of the edge of the vegetated area) or 'mid' (more than $\sim 20 \mathrm{~m}$ from the edge of the vegetated area). 


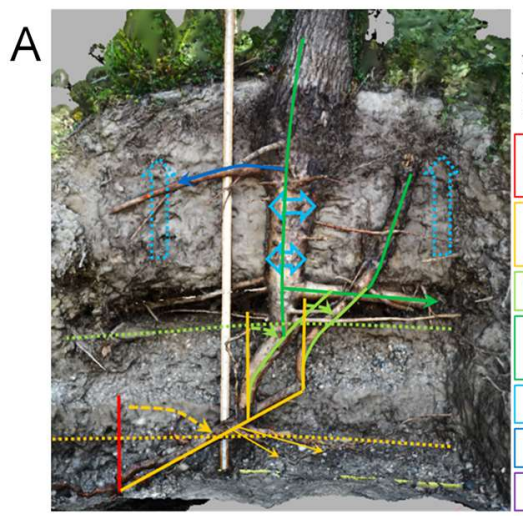

1980
Aerial photos show channel margin colonisation between 1986 and 1991. Recruitment model
suggests 1988 a good year, though oldest roots only pre-1994. However, original roots may have died.
Stem knocked down by flood. Gravel deposited. Two surviving vertical shoots carry on up from
lateral buds. Horizontal roots track along top of gravel as fines are deposited above
Two stems deflected by flood and embedded in further gravel deposits
Lateral bud becomes dominant on upstream shoot as apex dies back. This new shoot sends out major
new adventitious roots into accumulating fines. So does downstream shoot, but to a lesser extent
Site becomes increasingly sheltered as vegetation thickens considerably. Fine sediment accumulates
Highest large lateral root from main stem
Growth and deposition slow as canopy closes

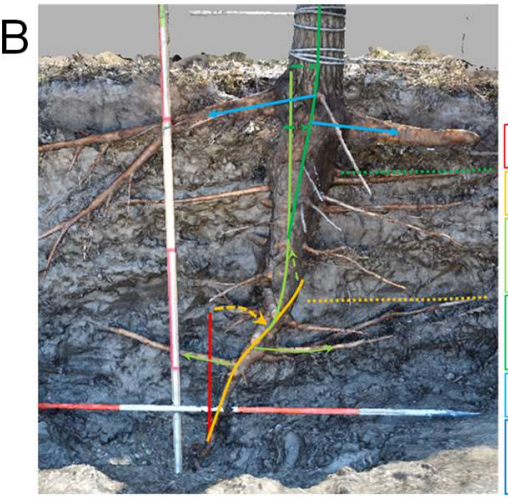

\begin{tabular}{|l|}
\hline Seedling or sucker establishes on gravelly substrate \\
\hline Young stem deflected and buried in flood \\
Apical meristem remains dominant shoot. \\
Laterals expand into newly deposited material \\
\hline $\begin{array}{l}\text { Stem (now quite stout and well-established) given slight deflection } \\
\text { by late 2000 flood. Further deposition }\end{array}$ \\
\hline Laterals expand into upper strata. Period of little or no deposition \\
\hline Upper laterals put on more compression wood as main channel encroaches \\
and begins to cause erosion at the site
\end{tabular}

Fig. 3. Interpretation of the development of the main underground axis and large lateral roots of (A) tree $\mathrm{N} 1$ and $(\mathrm{B})$ tree $\mathrm{N} 2$ in relation to the history of flow disturbances.

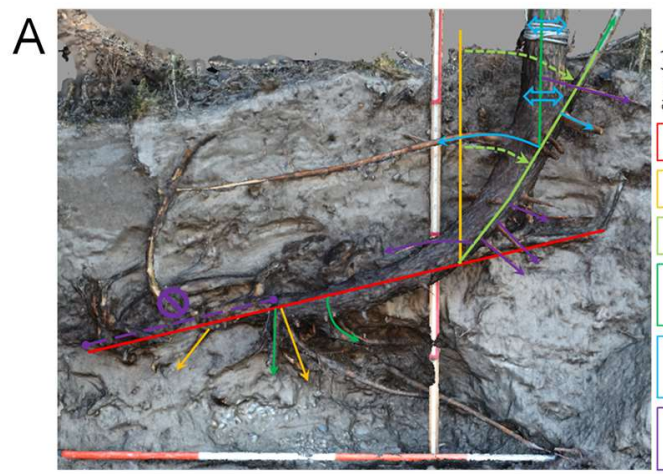

\begin{tabular}{|l|}
\hline Parent tree eroded from bank and redeposited \\
\hline Lateral bud sprouts shoot. Roots emerge from lower side of deposited tree \\
\hline New main stem deflected and buried \\
\hline Dominant shoot emerges from lateral bud but previous axis survives and continues to grow \\
Production of more deep roots to support growing leaf area \\
\hline \begin{tabular}{l} 
Adventitious roots expand into deposits related to the winter 2004 flood \\
Extant (vertical) trunk becomes dominant over surviving part of parent stem \\
\hline Remnants of parent tree become disconnected by nylon cord and die back \\
Increased growth of adventitious roots above the cord to compensate
\end{tabular} \\
\hline
\end{tabular}

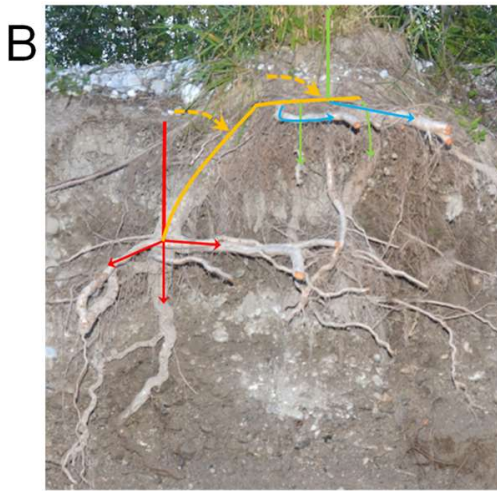

Establishes on old bar surface (possibly sucker from existing clonal root network)
Extends roots radially and downwards, seeking moisture below
Stem knocked down by flood, potentially in two phases. Gravel deposited
Upper part of deflected stem sprouts sinker roots and shoot which will become
the extant trunk
Lateral roots extend into fine deposits relating to 2000 and 2002 floods
Radial growth of stem slows as main channel encroaches and begins to erode the
bank

Fig. 4. Interpretation of the development of the main underground axis and large lateral roots of (A) tree N3 and (B) tree N4 in relation to the history of flow disturbances. 

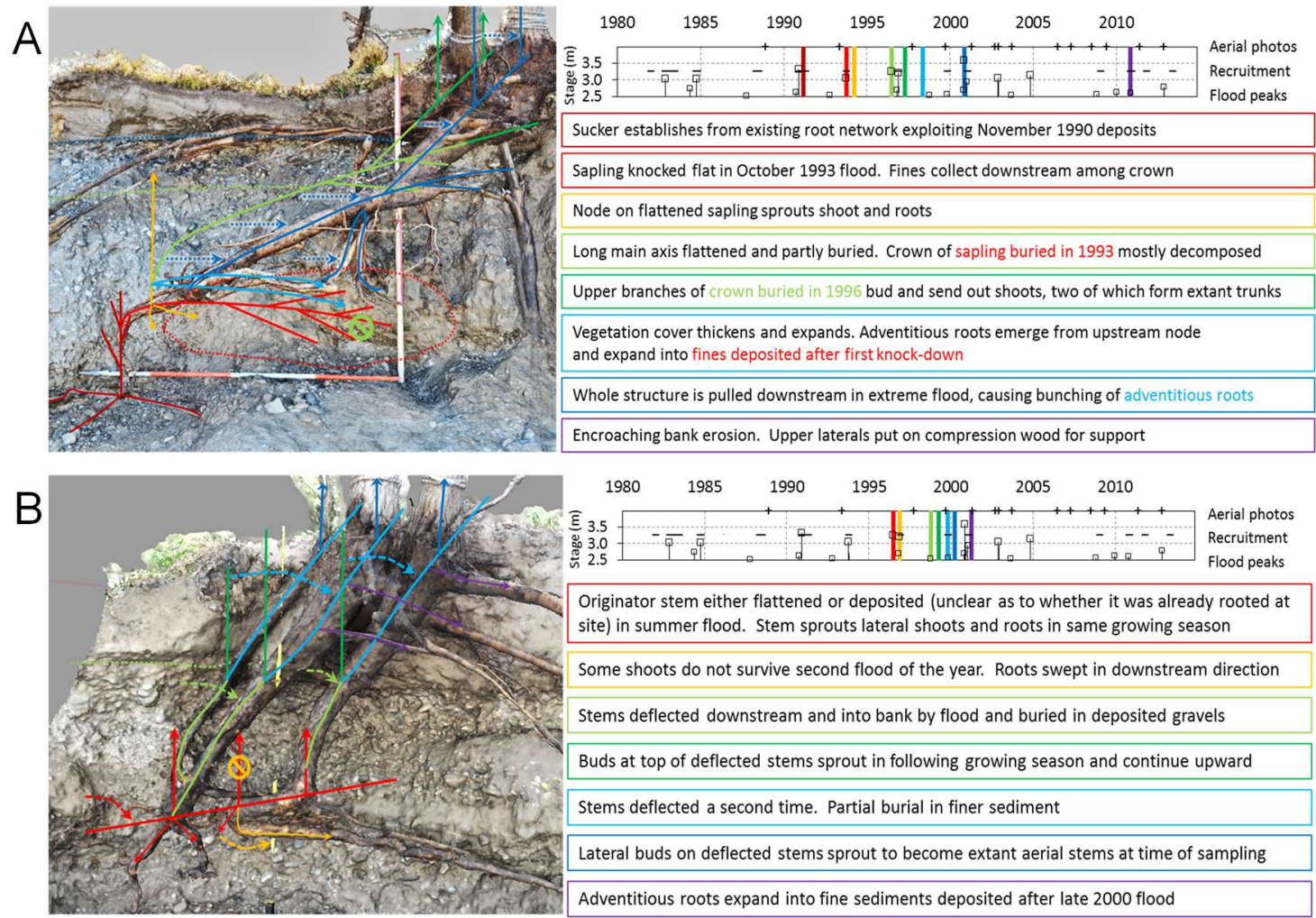

\begin{tabular}{l}
1980 \\
Some shoots do not survive second flood of the year. Roots swept in downstream direction \\
Site) in summer flood. Stem sprouts lateral shoots and roots in same growing season \\
\hline Buds at top of deflected stems sprout in following growing season and continue upward \\
\hline Stems deflected a second time. Partial burial in finer sediment \\
\hline Lateral buds on deflected stems sprout to become extant aerial stems at time of sampling \\
\hline Adventitious roots expand into fine sediments deposited after late 2000 flood \\
\hline
\end{tabular}

Fig. 5. Interpretation of the development of the main underground axis and large lateral roots of (A) tree $\mathrm{S} 1$ and $(\mathrm{B})$ tree $\mathrm{S} 2$ in relation to the history of flow disturbances.

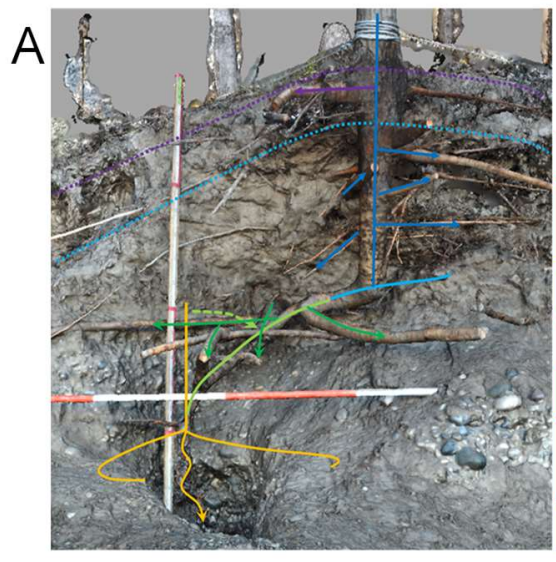

\begin{tabular}{l}
1980 \\
\hline Expansion of root network into fine deposits from 1996 floods \\
Sucker sent up and sinker root sent down \\
Original sucker flattened and buried \\
\hline Proliferation of adventitious roots into deposited fines \\
\hline Huge amount of deposition and burial in severe late 2000 flood \\
Main stem sucker sent up \\
\hline Highest lateral grows into late 2002 deposits. \\
\hline
\end{tabular}

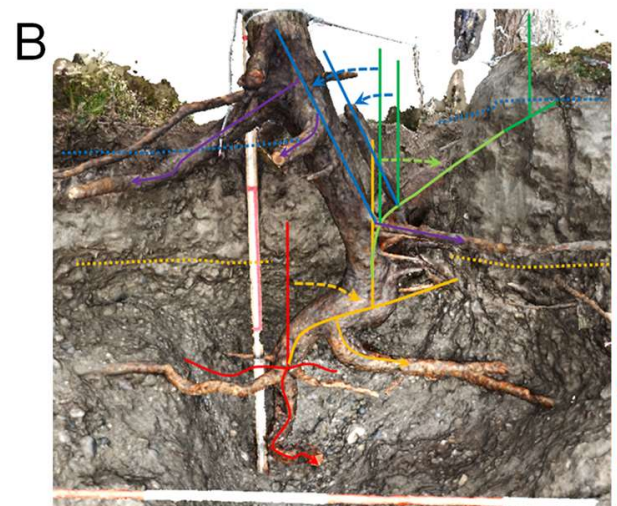

1980
Lnitial propagule establishes on bar surface and sprouts shoot and taproot
shoot and large root on lower surface (mid-growing season flood)
Shoots which will later form main trunks (and subsidiary stem dead at excavation) sprout
Dramatic expansion of vegetation at site evident from aerial images
Large amount of deposition in late 2000 flood
Near two stems destabilised and develop lean
Adventitious roots expand into flood deposits

Fig. 6. Interpretation of the development of the main underground axis and large lateral roots of (A) tree S3 and (B) tree S4 in relation to the history of flow disturbances. 
Table 1

Summary of observed features of tree buried stem and coarse root morphology, age, and associated sediments (from Holloway et al., 2016)

\begin{tabular}{|c|c|c|c|c|c|c|c|c|}
\hline Tree & N1 & N2 & N3 & N4 & S1 & S2 & S3 & S4 \\
\hline Latitude (degrees) & 46.23794 & 46.22428 & 46.20108 & 46.20632 & 45.93784 & 45.93609 & 45.93468 & 45.93320 \\
\hline Longitude (degrees) & 13.04350 & 13.03729 & 12.97370 & 12.98691 & 12.90416 & 12.90407 & 12.90443 & 12.90451 \\
\hline $\begin{array}{l}\text { Vertical stem growth } \\
\text { rate from } 1.2 \mathrm{~m} \\
\text { above ground } \\
\text { surface }\left(\mathrm{m} . \mathrm{y}^{-1}\right)\end{array}$ & 0.9 & 0.7 & 1.1 & 1.0 & 0.7 & 0.8 & 1.0 & 1.0 \\
\hline $\begin{array}{l}\text { Radial stem growth } \\
\text { rate at } 1.2 \mathrm{~m} \text { above } \\
\text { ground surface } \\
\left(\mathrm{mm} . \mathrm{y}^{-1}\right)\end{array}$ & 5.7 & 3.4 & 4.8 & 5.8 & 4.7 & 5.7 & 5.6 & 4.4 \\
\hline $\begin{array}{l}\text { Minimum rooting } \\
\text { depth }(m)\end{array}$ & 1.8 & 1.8 & 1.8 & $1.4 ?$ & 2.0 & 1.9 & 1.9 & 1.3 \\
\hline $\begin{array}{l}\text { Downstream } \\
\text { displacement of } \\
\text { main axis }(\mathrm{m})\end{array}$ & 1.1 & 0.6 & 1.4 & $1.0 ?$ & 2.8 & 0.9 & 0.9 & 0.3 \\
\hline Shape of main axis & $\begin{array}{l}\text { 3-section } \\
\text { inclined }\end{array}$ & inclined & curved & stepped & $\begin{array}{l}\text { mainly } \\
\text { inclined, } \\
1-\text { step }\end{array}$ & stepped & stepped & stepped \\
\hline $\begin{array}{l}\text { Step / section } \\
\text { boundaries in main } \\
\text { axis above junction } \\
\text { with coarser } \\
\text { sediment layer }\end{array}$ & yes & no steps & no steps & yes & yes & yes & yes & yes \\
\hline $\begin{array}{l}\text { More / larger lateral } \\
\text { roots present } \\
\text { immediately above } \\
\text { junctions with } \\
\text { coarser sediment } \\
\text { layers }\end{array}$ & yes & no steps & no steps & yes & yes & yes & yes & yes \\
\hline Roots grafted & no & no & no & yes & no & no & yes & no \\
\hline $\begin{array}{c}\text { Stem at } 1.2 \mathrm{~m} \text { older } \\
\text { than roots }\end{array}$ & yes & yes & no & yes & yes & yes & yes & yes \\
\hline $\begin{array}{c}\text { Stem at } 1.2 \mathrm{~m} \text { dates } \\
\text { to (before) }\end{array}$ & 1994 & 1996 & 2003 & 2001 & 1999 & 2000 & 2002 & 1998 \\
\hline $\begin{array}{l}\text { Oldest below ground } \\
\text { age (before) }\end{array}$ & 1994 & 1992 & 2001 & 1999 & 1993 & 1995 & 1997 & 1994 \\
\hline $\begin{array}{l}\text { Estimated flood } 1 \\
\text { (before) }\end{array}$ & 1996 & $\begin{array}{l}\text { early } \\
1990 s\end{array}$ & 2005 & $\begin{array}{l}2000- \\
2001\end{array}$ & 1993 & $\begin{array}{l}\text { mid } \\
1990 s\end{array}$ & 1999 & 1996 \\
\hline $\begin{array}{c}\text { Estimated flood } 2 \\
\text { (before) }\end{array}$ & 1998 & $2002 ?$ & & 2003 & 1996 & $\begin{array}{l}\text { late } \\
\text { 1990s }\end{array}$ & $\begin{array}{l}2000- \\
2001\end{array}$ & 2000 \\
\hline $\begin{array}{l}\text { Estimated flood } 3 \\
\text { (before) }\end{array}$ & & & & & $\begin{array}{l}\text { Late } \\
\text { 1990s }\end{array}$ & & & \\
\hline
\end{tabular}


Table 2

Sources and dates (where known) of images analysed

\begin{tabular}{|c|c|c|}
\hline Image year & Image date & Source \\
\hline 1944 & July 25, 1944 & The Aerial Reconnaissance Archives, Keele University \\
\hline 1946 & Not known & The Aerial Reconnaissance Archives, Keele University \\
\hline 1954 & April 11, 1954 & Istituto Geografico Militar \\
\hline 1954 & May 15, 1954 & Istituto Geografico Militar \\
\hline 1966 & November, 1966 & Autorita` di Bacino dei fiumi dell'Alto Adriatico \\
\hline 1970 & Not known & Autorita` di Bacino dei fiumi dell'Alto Adriatico \\
\hline 1986 & December 24, 1986 & Istituto Geografico Militar \\
\hline 1988 & November 21, 1988 & Regione Friuli Venezia Giulia \\
\hline 1991 & October 8, 1991 & Rossi s.r.I. REVEM Brescia \\
\hline 1993 & May 10, 1993 & Regione Friuli Venezia Giulia \\
\hline 1993 & July 16, 1993 & Source unknown \\
\hline 1996 & Not known & AIMA del Ministero delle Politiche Agricole Alimentari e Forestali \\
\hline 1997 & June 16, 1997 & Autorita`di Bacino dei fiumi dell'Alto Adriatico \\
\hline 1997 & September 16, 1997 & Autorita` di Bacino dei fiumi dell'Alto Adriatico \\
\hline 1999 & September 11, 1999 & Autorita`di Bacino dei fiumi dell'Alto Adriatico \\
\hline 2001 & April 9-13, 2001 & Autorita` di Bacino dei fiumi dell'Alto Adriatico \\
\hline 2002 & July 21, 2002 & DigitalGlobe \\
\hline 2002 & September 14, 2002 & DigitalGlobe \\
\hline 2002 & November 30, 2002 & Autorita` di Bacino dei fiumi dell'Alto Adriatico \\
\hline 2003 & $\begin{array}{l}\text { September 14/27, } \\
2003\end{array}$ & Regione Friuli Venezia Giulia, DigitalGlobe \\
\hline 2005 & May 23, 2005 & Natural Environment Research Council UK \\
\hline 2006 & June 13, 2006 & Department of Geography, University of Padova \\
\hline 2007 & April 12, 2007 & Department of Geography, University of Padova \\
\hline 2008 & June 25, 2008 & European Space Imaging \\
\hline 2009 & May 14, 2009 & Department of Geography, University of Padova \\
\hline 2011 & May 19, 2011 & DigitalGlobe \\
\hline 2012 & March 2, 2012 & DigitalGlobe \\
\hline 2012 & October 23, 2012 & Department of Geosciences, University of Padova \\
\hline
\end{tabular}


Table 3

Comparison of estimates of recruitment and disturbance dates based on morphology, dendrochronology, and sediment (morphology) with estimates of dates further refined using historical process information (processes) (note that the dates inferred from morphology are the latest dates before which the event may have occurred and those for recruitment reflect earliest dates of the buried components of the studied tree)

\begin{tabular}{|c|c|c|c|c|c|c|c|c|c|}
\hline & $\begin{array}{l}\text { Dating } \\
\text { source }\end{array}$ & N1 & N2 & N3 & N4 & s1 & $\mathbf{S 2}$ & S3 & S4 \\
\hline \multirow[t]{2}{*}{ Recruitment } & $\begin{array}{l}\text { morphology } \\
\text { (before) }\end{array}$ & 1994 & 1992 & 2001 & 1999 & 1993 & 1995 & 1997 & 1994 \\
\hline & $\begin{array}{c}\text { processes } \\
\text { (recruitment) }\end{array}$ & 1988 & 1988 & 2000 & 1996 & 1991 & 1996 & 1996 & 1993 \\
\hline \multirow[t]{2}{*}{$\begin{array}{c}\text { Flood } \\
\text { disturbance } \\
1\end{array}$} & $\begin{array}{l}\text { morphology } \\
\text { (before) }\end{array}$ & 1996 & $\begin{array}{l}\text { early } \\
1990 s\end{array}$ & 2005 & $\begin{array}{l}2000- \\
2001\end{array}$ & 1993 & $\begin{array}{l}\text { mid } \\
1990 s\end{array}$ & 1999 & 1996 \\
\hline & $\begin{array}{c}\text { processes } \\
\text { (disturbance) }\end{array}$ & 1990 & 1990 & 2002 & 2000 & 1993 & 1998 & 1998 & 1996 \\
\hline \multirow[t]{2}{*}{$\begin{array}{c}\text { Flood } \\
\text { disturbance } \\
2\end{array}$} & $\begin{array}{l}\text { morphology } \\
\text { (before) }\end{array}$ & 1998 & 2002 & & 2003 & 1996 & $\begin{array}{l}\text { late } \\
1990 s\end{array}$ & $\begin{array}{l}2000- \\
2001\end{array}$ & 2000 \\
\hline & $\begin{array}{c}\text { processes } \\
\text { (disturbance) }\end{array}$ & 1993 & 2000 & & 2002 & 1996 & 1999 & 2000 & 1996 \\
\hline \multirow[t]{2}{*}{$\begin{array}{c}\text { Flood } \\
\text { disturbance } \\
3\end{array}$} & $\begin{array}{l}\text { morphology } \\
\text { (before) }\end{array}$ & & & & & $\begin{array}{l}\text { late } \\
1990 \mathrm{~s}\end{array}$ & & & \\
\hline & $\begin{array}{l}\text { processes } \\
\text { (disturbance) }\end{array}$ & & & & & 2000 & & & \\
\hline
\end{tabular}

